AperTO - Archivio Istituzionale Open Access dell'Università di Torino

\title{
Storytelling on mobile devices for cultural heritage
}

\section{This is the author's manuscript}

Original Citation:

Availability:

This version is available http://hdl.handle.net/2318/101560

since 2016-06-29T11:58:59Z

Published version:

DOI:10.1080/13614568.2012.617846

Terms of use:

Open Access

Anyone can freely access the full text of works made available as "Open Access". Works made available under a Creative Commons license can be used according to the terms and conditions of said license. Use of all other works requires consent of the right holder (author or publisher) if not exempted from copyright protection by the applicable law. 


\title{
RESEARCH ARTICLE
}

\section{Storytelling on mobile devices for cultural heritage}

\author{
Vincenzo Lombardo $^{a, b *}$ and Rossana Damiano ${ }^{a}$ \\ ${ }^{a}$ CIRMA, Università di Torino, Torino, Italy; ${ }^{b}$ Virtual Reality \& Multi Media Park, \\ Torino, Italy
}

(Received 00 Month 200x; final version received 00 Month 200x)

\begin{abstract}
This paper illustrates a storytelling-based application for an anthropomorphic guide to a historical site, presented through a mobile device. We discuss the requirements posed by the communication context and the idea of approaching the problem through storytelling. Then we describe the application, that merges the basic structure of storytelling with the requirements coming from the communication of the specific knowledge about the historical site, the user interaction issues concerning the target audience and the technological issues posed by the mobile device. Finally, we address the evaluation issues and we discuss the results with respect to storytelling.
\end{abstract}

Keywords: storytelling; mobile device; virtual character; cultural heritage

\section{Introduction}

This paper is about the use of storytelling techniques on mobile devices for guiding the visit to cultural heritage sites. The paper stems from the design, implementation and evaluation of a mobile-based, virtual guide to a historical site (published in Damiano et al. (2008) and Lombardo et al. (2008)), and illustrates how the constraints posed by the application requirements - such as the fact of being delivered on a mobile device, implying a situated interaction with the user, and having cultural heritage as domain - have shaped the storytelling elements in the application, concluding with the lesson learned.

In the last decades, there has been a trend towards the active participation of people visiting historical locations. This trend has been partially sustained by what Malcolm-Davies (2004) calls "a discernible shift from historical monument to heritage product", that has resulted in encouraging the visitors' request for more involvement. In particular, the request for more involvement has lead curators to devise a number of activities that range from first person interpretation, employing costumed staff that portrays historical characters, to second-person curricula, with visitors playing roles connected with past everyday life in the historical site, to third person storytelling, where the staff tells stories about the site (Magelssen 2006). When some historical site demands for the accommodation of multiple points of view, a first person personalized storytelling, represented as a dramatic "object theatre" was proposed as an instrument for mediation (Ashley 2007).

\footnotetext{
*Corresponding author. Email: vincenzo.lombardo@unito.it
} 
This trend is in line with the most recent tendencies of new media (virtual reality, games, interactive digital storytelling), where the innovation in graphic capacities, computing resources and connectivity have opened the way to effective experimentations on immersivity in virtual environments and augmented realities. ${ }^{1}$

At the junction of the enlivening strategies for cultural heritage and new media are a number of mixed reality approaches that rely on technology for conveying information and engage visitors in museums and heritage sites. This line of development is constantly investigated in major institutions around the world, as exemplified by the "Museum and the Web" conferences. ${ }^{1}$ By surveying these approaches, storytelling emerges as a major paradigm for building cultural heritage applications. However, in situated environments, storytelling must cope with the requirement of interactivity and the constraints posed by the physical location. For example, in a historical site, the story must dynamically adapt to the trajectories followed by the visitor.

An alternative approach, naturally oriented to mobility, is the paradigm of pervasive games (Ericsson (2003), Montola et al. (2009), Gentes and Jutant (forth), in this issue). Pervasive gaming employs mobile devices like PDAs and smartphones to manage large-scale role playing, thus providing a recreational and engaging way to interact with cultural heritage sites. In pervasive games, users, by performing situated tasks, contribute to the achievement of some plot, devised by the game designer, but have a more active role with respect to storytelling, partly because the plot advancement is not the main purpose of the game, but is obtained as a by-product of a goal-directed playing experience. Since the actual visit to a historical location still remains the main modality of fruition of cultural heritage, the paradigm of pervasive gaming has been successfully adopted to intrigue visitors about the historical background of cultural heritage sites (see Reid et al. (2008), Ballagas et al. (2008)).

In this paper, we address the storytelling paradigm in a mobile context in a more traditional way, namely as a third-person "performed narration" of a single character, in an augmented reality scenario. We tell of a practical application, a storytelling-based application, with limited interactivity, conceived for a specific location and mobility setting, called "Carletto the spider". The application realizes a single-character dramatic performance, staged on a mobile device, that aims at guiding a visitor to a historical site. Carletto is a virtual guide for the historical location of Palazzo Chiablese in Turin, Italy. The building hosts the former royal apartments of the Savoy family. The character is an anthropomorphic spider (Figure 1), who lives hidden in the apartments. His image is captured by a webcam and delivered to the visitor's mobile device (a PDA) via a wireless network. Carletto is the last descendant of a noble family of spiders, inhabiting the palace for centuries; like his ancestors, he has been annotating the relevant facts about the palace in a web, that he inspects for retrieving his memories, checking dates, etc. The production of "Carletto the spider" follows a standard approach in computer graphics, with character design, mise-en-scène, individual unit production and editing. The character "Carletto" was designed and realized in 3D graphics, following the specifications given by the author. It is not rendered in real-time computer graphics, but audiovisual units, rendered off-line, were edited in real-time to produce a fluent video. The clip associated with each unit lasts between 15 and 50 seconds. The installation was open to the general public for one week in April 2006, and

\footnotetext{
${ }^{1}$ See, e.g., Molineux' Milo character at http://www.ted.com/talks/lang/eng/peter_molyneux_demos_milo_the_virtual_boy.html) ${ }^{1}$ See, e.g., the survey at http://www.learningtimes.net/museums-mobile/archive/surveyresults-2009/ and the sessions and workshops at the "Museum and the Web" conferences, http://www.archimuse.com/mw2010/pdfs/mw2010-finalProgram.pdf
} 
the system evaluation, carried out through 300 anonymous questionnaires and an ethnographic observation, demonstrated that people, on the one side, liked Carletto and were emotionally engaged with his story, and, on the other, were quite satisfied with the content delivery, also in comparison with the human and the audio guides, respectively (Damiano et al. 2008).

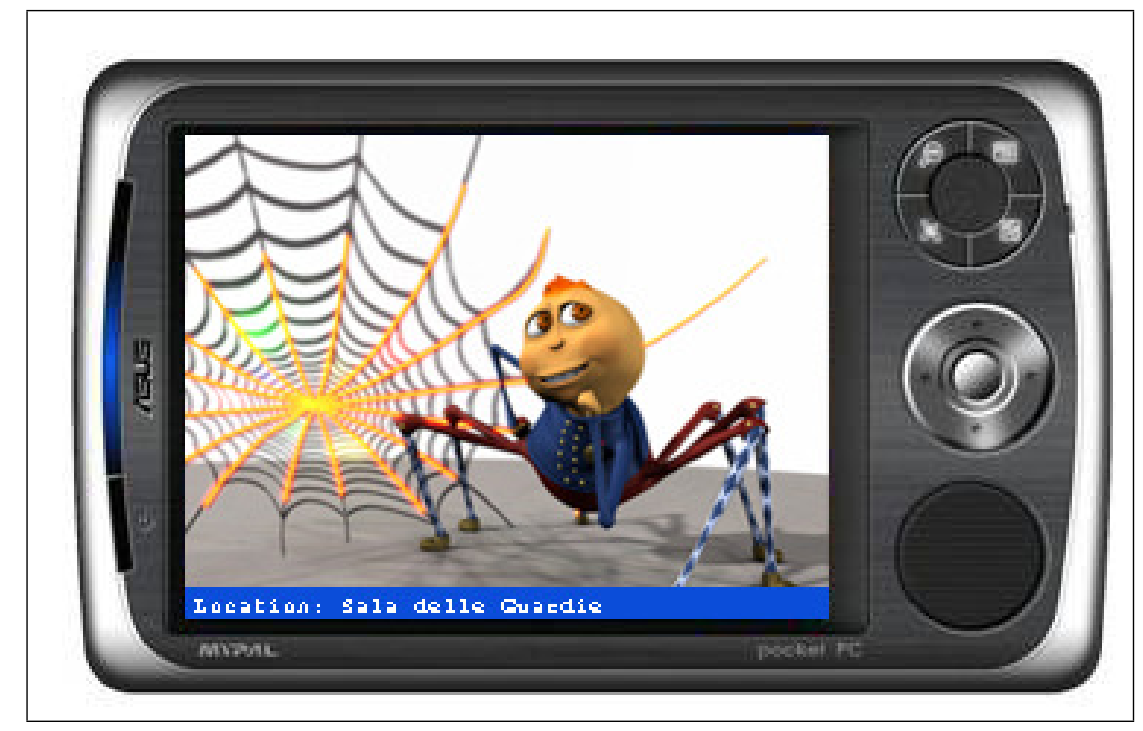

Figure 1. "Carletto the spider"

Given the design, implementation, and evaluation of "Carletto the spider", we analyze the challenges raised for the storytelling paradigm by the requirements of interactivity and mobility and by the informative goals of the cultural institution that manages the historical site. The paper starts by introducing the basic tenets of traditional storytelling and how such tenets have evolved in computational systems, with emergent narratives based on the effective modeling of characters, the recreational perspective put forth by the paradigm of pervasive gaming, and the adaptation of storytelling to the communication goals of a cultural heritage institution. Then we focus on our case study, that we analyze in terms of traditional storytelling and the challenges of interactivity, mobility and informative goals raised by the specific context, with the solutions consequently adopted. Finally, we discuss the findings and perspectives with respect to storytelling.

\section{Location-aware Storytelling: Background and Motivations}

The importance of storytelling for the transmission of information is acknowledged by several scholars across different disciplinary fields. Psychologists, such as Bruner (1991), claim that stories provide a framework for making sense of events and convey the values of a culture. Communication specialists, such as Gershon and Page (2001), claim that stories can convey large amounts of information in a compact format, easily assimilated by the user. According to literary studies (Prince 2003), storytelling develops along two orthogonal axes, which characterize each story: characters and plot. The plot contains a series of incidents, made of characters' actions and unintentional events, connected through a causal chain. The mechanism of identification with the characters (Carroll 2001), that sustains the emotional participation to the story, typically requires characters to exhibit a certain predictability of behavior, while facing troubles that challenge the achievement of their object of desire (McKee 1997). So, while the plot forces characters 
to react to the troubling events by adapting her/his behavior to the context, they must stick to their established long-term goals to maintain believability.

In linear stories, such as cinema or fictional video, the author carefully designs the story incidents to keep the right balance between the turning points of the plot and the characters' stability of behavior. In interactive storytelling, where stories are generated on-the-fly, the authorial control on the story is weakened. Architectures for interactive digital storytelling rely on a factorization of the story into basic units, that are edited online to form a sequence that depends on the input provided by the user. Given the traditional dichotomy between character and plot, these architecture can incorporate a character-based or a story-based narrative model. The approach of emergent narrative relies on characters: the author creates the characters, sets up a scenario that challenges the characters and lets them improvise, possibly constraining their behavior to follow a gross-grained script ( $\mathrm{Si}$ et al. (2005), Mateas and Stern (2005)). In this case, the units manipulated by the system are the characters' actions. In template-based approaches (Thomas and Young (2006), Nelson et al. (2006)), units containing story events are created in advance and assembled according to some author's direction, expressed in some formal language (templates, constraints, etc.). The underlying story model is often derived from the narrative theories proposed by semiotic structuralism, like those of Propp (1968) and Greimas (1977). It is worth noting that - whatever the chosen approach - these techniques are made possible by the explicit annotation of the story units in terms of characters' traits (goals, behaviors, personality) and story segment description (applicability conditions and effects of each segment). Given this annotation, the system is able to select the most appropriate story continuation according to its narrative model.

Independently of the specific narrative model, the primary role assigned to characters in narratological studies is acknowledged by interactive digital storytelling through a shared, explicit notion of character. In interactive storytelling, artificial characters have a twofold function: On the one side, they are the medium through which the story is conveyed to the audience, since they perform the live actions that make the story advance); on the other side, they are the necessary condition of the interaction with the user (Spierling 2005), since they provide the interface between the system and the audience (cf. the "computer as theatre" metaphor as the main modality of the human-computer interaction theorized by Laurel (1993)).

In human-computer interaction, the design of sophisticate characters has proven to be effective in improving the naturalness of the interaction between software systems and users, making systems appear more responsive and cooperative. For example, the "embodied" conversational characters (ECAs) engage the users in a social interaction that includes natural language dialogue and non verbal communication, such as gaze, gestures, etc. (see the survey by Bickmore and Cassel (2005)). The methodology for building artificial characters ranges from synthesizing their behavior after an abstract specification of the character to assembling predefined behavior units (Bernsen and Dybkjaer (2004), Kopp et al. (2005), Swartout et al. (2010)). As far as their appearance is concerned, then, improved sound and graphic processing has provided virtual characters with realistic facial expressions and lipsynch speech that display emotions for pedagogical aims (Leon and Fisher 2006). On the complementary perspective of film and game industries, the CG animated characters (Maestri (1996), Clark (2002)) are finely modeled and rendered, move, talk, and speak in realistic manner, and are endowed with full-fledged, sophisticate personalities. All these factors contribute to create Coleridge's "suspension of disbelief", that characterizes fictional narration and favors identification and immersion by the user. 
In cultural heritage, the paradigm of storytelling has been extended to location awareness so as to extend the interactivity to the heritage location. In location aware storytelling, a story is interactively generated taking the user location as input. For example, in the pioneering application described by Pletinckx et al. (2003), the story is a sequence (a "ring") of facts (called "nuggets"), connected by temporal and content links such as before, after, similar and so on, anchored in the spatial trajectory followed by the user. In the application designed for the Historic Oakland Cemetery in downtown Atlanta by Dow et al. (2005), the physical environment is the base for delivering to the audience an audio-based dramatic experience in which the ghosts of the cemetery residents tell stories about the periods in which they lived.

Location-awareness is shared with another relevant paradigm for cultural heritage applications, namely pervasive gaming. The qualities that mobile devices add to games, surveyed by Ericsson (2003) as mobility, location, presence and communication, make pervasive gaming a suitable paradigm to develop location-aware games for historical locations (see for example Ballagas et al. (2008), Reid et al. (2008), Stenton et al. (2007)). In pervasive games, the physical location must become an intrinsic part of its diegetic component. As a consequence, the game must be carefully designed so as to provide actual locations a role in the game advancement (Ericsson 2003 Hansen et al.): a violation of this principle may lead to a disruption in the player's immersion into the game. Consistently with this principle, applications of the paradigm of pervasive gaming to cultural heritage superimpose a virtual story world to the physical space, reviving a distant era through the use of sound and images on hand held devices. Practical examples of such historical games range from competitive games, such as the Prisoner Escape from Tower, designed for the location of the London Tower and its surrounding (Reid et al. 2008), to narrative oriented ones, such as the REXplorer game (Ballagas et al. 2008). The latter, set in the medieval German city of Regenburg, is posited at the junction of interactive storytelling and pervasive gaming, with virtual characters from the past asking the players to accomplish tasks in their favor, while taking the opportunity to tell stories about themselves. Finally, Hansen et al. (forth) rely on a dramaturgical model for the design of their mobile drama in a urban environment (in this issue).

\section{Challenges to storytelling}

The scenario in which mobile-based, storytelling applications for cultural heritage take place is characterized by active users, who move around in a physical place (mobility) and act upon technological devices that bring their own limitations into the interaction with the user. In particular, it is important to keep in mind that, in cultural heritage, storytelling is functional to the goal of conveying information to the visitors (informative goals), an issue that derives from the specific commitment of cultural institutions toward dissemination.

In order to keep storytelling consistent notwithstanding the challenges of a mobile, interactive setting, the consistency of the character and the coherence of the plot must be preserved by resorting to some carefully designed form of adaptation. The solution adopted in "Carletto the spider" is to subordinate storytelling to the guidance issues and the conversational attitude of the character, making the role of the museum guide to prevail over the role of the gossipy resident. So, users are provided with a clearly recognizable metaphor, the one of the guided visit, that motivates the character's guidance, though addressing the character's inner conflict (with his dramatically relevant gossipy soul) in the scriptwriting process (Damiano 
et al. 2006).

In this section, we detail out the adaptation process of the storytelling approach within the whole system. Given the survey above, four main elements emerge as challenges for the storytelling in location-aware applications. First, some challenges are inherited from the inspiring paradigms of interactive digital storytelling and pervasive gaming:

- Interactivity is intented as users making actions that affect the application, in a more or less intentional way, like for example using the mobile device to perform actions in the story world (e.g. Ballagas et al. (2008)), or simply moving from a location to another (e.g. Dow et al. (2005)). Linear storytelling must cope with this challenge, devising ways (such as metaphors and plot devices) to turn potential inconsistencies introduced by interactivity into elements of the story. This constraint matches the quality of "mobility" that Ericsson (2003) points out as one of the characterizing features of pervasive games (.i.e. players doing things in the real world as part of the game).

- Mobility: Site topology and mobile technology constrain the design choice. For example, consider the scale of specific topology and the granularity of the localization allowed for by the mobile technology. Since the scale may range from a city to a single apartment, it implies different design choices at the storytelling level: for example, a restricted location is not likely to host many different narrating agents, while it is perfectly suitable to associate different buildings and sites with several (virtual) characters. In Ericsson's terms, mobility equates to "location" and "presence", respectively, the quality that allows the (game) application to superimpose virtual entities to the physical space, and the quality that consists in the presence of the user in a physical environment, with its own appearance and constraints.

A second type of challenges derives from the specific requirements posed by the specific domain of cultural heritage: these challenges have to do with the practical aspects shared by the applications designed for this domain (situatedness, device constraints, etc.) and by their basic inspiring goal of cultural dissemination.

- Informative goals: e.g. conveying information and knowledge or guidance: the storytelling application typically fulfills other needs than user engagement in a story. In cultural heritage, most applications, independently of the paradigm they adopt - be it a pervasive game or interactive storytelling -, have the primary goal to convey information, even when the entertainment finality is outstanding (Reid et al. 2008). This goal cannot be straightforwardly mapped to any quality of pervasive gaming.

- Technology and setting: the site topology, the hardware and software specifications of the mobile device, the participating institutions, all introduce additional constraints to the design of the location-based storytelling. The device, being primarily a communication and computing device, brings with it a suite of functions and technological constraints the storytelling must cope with, such as modality, supported media, etc. Different storytelling applications rely on different media contents, depending on the degree of intended intrusiveness, on the need to preserve the users' focalization or drive her/his attention. This roughly corresponds to the quality of "communication" - intended as communication between players and game characters - in Ericsson's analysis of pervasive gaming. Finally, the constraints posed by the cultural heritage curators to the use of technologies on site are also very relevant to shape the applications.

In the following, we describe the requirements posed by the challenges described 
above for the development of mobile storytelling applications for cultural heritage and discuss how we addressed them in the development of "Carletto the spider". We start from the informative goals, provided by the institution, that define the information to be conveyed and the design goals of the system; second, we analyze the interaction strategy that drives Carletto's communcative and social behavior; third, we go inside the story generation through the automatic editing of units, describing their ontology-based annotation and retrieval; finally, we address the technological infrastructure and its limitations for storytelling, describing how they have been turned into scripted tricks for engaging the audience.

\subsection{The challenge of informative goals}

The main challenge to storytelling comes from the informative goals that the hosting institution, who commissions the application, has in mind. In particular, in the domain of cultural heritage, the institution gives priority to the goal of informing the visitors about the historical and artistic qualities of the site as part of the visit; as a consequence, the storytelling is subordinated to the guidance of the visit. Moreover, informative goals must be reconciled with the attractiveness of the communicative strategies, so as to attract visitors and keep them engaged from the emotional point of view. The achievement of informative goals, then, must take into account the spatial and temporal constraints posed by the site typology, by the preservation issues and by the organizational aspects of the maintenance of the site.

So, we can sum up the requirements for the storytelling application:

- spatial: being aware of the visitor's location during the visit and delivering appropriate content for the location, taking into account the topological structure of the site and the possible path of visit;

- temporal: constraining the visit to finish within a certain amount of time, possibly imposing a duration to some subparts of the visit;

The narration is a sequence of audiovisual units, edited on-the-fly to adapt to the user behavior and location. The segmentation into units, derived from traditional practice in writing and filming (see Section 2, is necessary where the actual succession of units depends on interactivity and motion (the permanence time of a visitor in a location, her/his individual trajectory, her/his explicit input through interface commands, etc.). Given a unit in display at a certain point, the application selects one of the possible continuations given the state of the application and the available units. To support the selection mechanism, units are annotated with the information about how they contribute to the character's behavior and the story progression. The compelling requirements of space and time to storytelling where addressed as follows.

Concerning the spatial requirements, the topology of the apartment prevented the possibility of organizing a linear path for the visitors, since the rooms were not pipelined (see map in Fig. 2); so, the visitors could stroll freely in the apartments, with the possibility of going back to one or more rooms if they felt like. The localization of the user relied on a wireless network that was already active in the apartments. So, we decided to accommodate the location changes of the user into the storytelling paradigm, and to base the coherence of the story being told on the topological structure of the site. To address the location changes, we devised the metaphor of the "webcam" to support the interaction with the character: the character, hidden in the ceiling among his webs, traces the visitor through his webcam, and communicates with her/him through the mobile device, following 


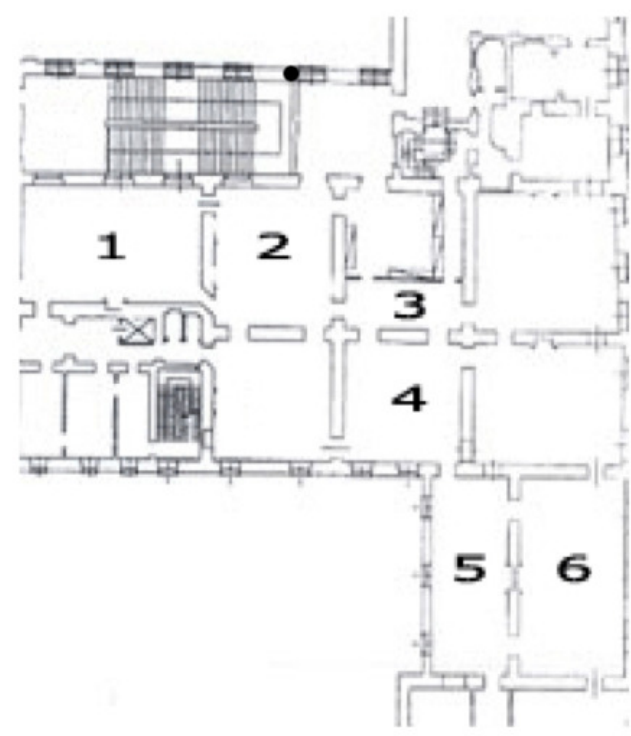

1 Guardroom

2 Room of the Valets

3 Corridor

4 Reception Room

5 Dining Room

6 Room of the Tapestries

Figure 2. The map of the Royal apartments of Palazzo Chiablese.

her/him from a room to another and acknowledging the changes. By doing so, Carletto's fictional word is superimposed to the real world (in accordance with the prescription of the paradigm of pervasive games) and the information he gives is contextually relevant to the current room because he follows the visitor along the visit.

Although the user interface does not support any forms of explicit input beyond the device controls, the duration of the stay of the user in a certain location is interpreted by Carletto as a sign of interest in the location, so he keeps delivering more and more specific information about that location, according to a commonly agreed upon general-to-particular focusing strategy (Grosz and Sidner 1986). Some information is retained in case the visitor returns to the location later. Explicit input, such as pressing the on/off device commands - as well as exceptions due to failures - are accommodated by the interactional behavior of the character, as described below in more detail.

Concerning temporal constrains, both the duration of the overall stay in the site and the duration of the stay in the single location have been accounted for. As it happens in most concrete realizations of a stories, "Carletto the spider" featured a time duration, established by the request from the cultural institution to limit the visit duration to about half an hour. The visitors were free to stroll in the apartments with the mobile devices, visiting the rooms according the order they preferred and going back to the already visited rooms if they wanted. The duration of the visit ( 25 minutes approximately) has been interwoven in the character design, by having the character invite the visitor to another room, as a consequence of his fear of being trapped by the cleaners. By doing so, the character's conflict with an antagonist (the cleaners), functional to engaging the user's identification with the character, becomes at the same time an instrument to regulate the duration of each phase of the visit and, as a consequence, of the overall visit itself.

\subsection{The challenge of interactivity}

In the application "Carletto the spider" storytelling is subordinated to the interactional behavior of the character. The visitor, in fact, can take control at any time, 
either implicitly, by moving to another room, or explicitly, by closing or pausing the application; so, the system must cope with the visitor's behavior by displaying a believable social and communicative behavior. The narration flows with a steady behavior of the visitor, but Carletto is ready to react to the variations caused by the visitor (or the environment) through an annotated script designed by the author of the application. In mobile drama, the approach of encoding the authorial direction in some formal structure is shared also with Hansen et al. (forth), who use plot graphs to structure the drama development: the conditional script designed for Carletto, although declared in a different form, is similar to an implicit graph.

The script accounts for the visitor's behavior, interpreting her/his action, including the location changes, as parts of the "guided visit" metaphor, where goals and behaviors of both character and visitor follow a well-known paradigm. However, the dramatic qualities of the character Carletto, with the two conflictual traits of his personality, cause the alternation between telling facts and anecdotes that occured in the palace and he (and his family) experienced in first person ("the first owner of the place, the marchioness Langosco, was the mistress of ..."), and professionally guiding the visit through a formal description of the rooms, their function, the historic events that took place in them and the artistic items they contain ("the paintings over the doors represent the ages of the human kind ...").

The issue of interactivity ('mobility' in Ericsson's terms Ericsson (2003)) challenges the flow of scripted alternations and poses the following requirements for the application:

- suitable interaction tools: providing the user with the ability to interact with the system in a simple an intuitive way;

- meaningful interaction: reacting with appropriate actions to the user input, thus building a socially coherent interaction (accomplished through a social script).

In order to meet the requirement of providing the visitor with suitable interaction tools, the interaction strategy of the character was designed as a sequence of communicative functions, borrowed from the paradigm of embodied conversational agents (see Section 2). Communicative functions belong to two main categories, reflecting the informative goals issued by the institution and the communicative strategy designed for the artificial character: the informative function consists in providing information about a certain topic; the interactional function encompasses all the acts that contribute to the interaction with the visitor (greeting, apologizing, etc.). The latter functions encompass the social function (basic social behaviors, like greeting or introducing oneself), the directive function (attempting to influence the user's behavior, like inviting her/him to another room), and the phatic function (displaying the character's presence without conveying any information).

The guided visit modeled script starts with Carletto introducing himself, a few units in which he alerts the visitor about his presence, tells his background, and prepares the visit. Then, the system proceeds by retrieving informative units to form a coherent sequence (general to particular), consistent with the location chosen by the visitor. Storytelling loses its priority in a number of cases that challenge the normal flow of the visit, only partly determined by the visitor's behavior:

(1) if the system detects that the visitor has remained in the current room for too long (given the visit duration, set as 25 minutes), Carletto enters a waiting loop in which he invites the visitor to a different room (again a directive function), and starts waiting for a reaction by alternating the character's idle state (phatic function) with new requests to move (e.g., Carletto polishes his medals and impatiently asks " what about changing room?");

(2) if the location of the visitor cannot be detected, Carletto invites the visitor to move in order to regain visibility (directive function); 
(3) if the visitor goes to the exit, Carletto switches to closing the interaction, taking leave from the visitor.

Given the schema above, each unit either achieves some communicative function, thus contributing to the character consistency, or accounts for some content topic concerning the location, thus contributing to the actual narration: for example, Carletto talking about some ancient resident of the apartments (informative unit), or Carletto introducing himself (social interaction unit). Unit annotation consists of a tripartite schema (Figure 3(a)), that includes information about the communicative function, the unit content, and the visual properties. For example, the unit in Figure 3(b) concerns the first landlady of the apartments (see the WORDS field).

There are three fields for annotation (see the example in Figure 3(a)):

- the communicative function accomplished by the unit: i.e. what sort of message is conveying the unit; the example unit is an informative unit;. In order to comply with the meaningful interaction requirement, the content of the unit is designed so as to make explicit the purpose of the unit itself, i.e., to make the communicative function explicit.

- the content of the unit, expressed through a topic ontology: i.e., what is the historical character, object, place, or event described in this unit; the example unit concerns the palace that contains the apartments (Palazzo Chiablese) and two characters (Beatrice Langosco and Carlo Emanuele I). The given/new distinction specifies whether the elements introduced in this unit are referred to as new or as already introduced (given) discourse elements in this unit; in the example, nothing is assumed as given and one historical figure is introduced as new;

- the video editing features of the unit: i.e. how the unit begins and ends in terms of the audiovisual features; in the example, the unit will begin with a long shot (LS) and the absence of Carletto's web, and will end with a close-up shot of Carletto and the presence of the web.

The first two sections (communicative function and content topic) concern the content of the individual unit, the last two sections (given/new and editing features) concern the relationship of the unit with other units to form a coherent audiovisual narration.

The directing instructions in Figure 3(b) are subdivided into a sequence of tripartite sections (five in this example):

(1) Carletto's acting is expressed in a compositional language; the individual action is encoded as an identifier that the animator interprets (e.g., C4 means that Carletto speaks with the right hand leaning on his chin - see Figure 1); the entire animation of the unit will be the acting sequence A2-C2-C4-E1-F1;

(2) the instructions for direction (camera control and scene) are encoded with a 5-tuple (the Figure 1 contains a frame of the third section): type of shot (LS = Long Shot, MS = Medium Shot, $\mathrm{CU}=$ Close Up), character orientation $(0=$ Front, $-90=$ Left side), position of the character in the frame (RIGHT_POS and CENTRE_POS are self-explanatory), camera motion (FIXED_CAMERA = camera in a fixed position, CENTRED_CAMERA = camera keeping the character in the center), presence of the spiderweb in the background (NO_WEB, WEB); this information will be used by the unit editor to form coherent sequences with respect to camera viewpoints;

(3) the words uttered by Carletto.

In summary, the challenge of interactivity is addressed by making storytelling subordinate to the task of guidance: this is implemented by encoding the behav- 


\begin{tabular}{|l|c|c|}
\hline \multicolumn{3}{|c|}{ ANNOTATION TAGS for INF_004 } \\
\hline $\begin{array}{l}\text { COMMUNICATIVE } \\
\text { FUNCTION }\end{array}$ & \multicolumn{2}{|c|}{ INFORMATIVE } \\
\hline \multirow{2}{*}{ TOPIC ONTOLOGY } & topological & historical \\
\cline { 2 - 3 } & Palazzo Chiablese & $\begin{array}{c}\text { Beatrice Langosco } \\
\text { Carlo Emanuele I }\end{array}$ \\
\hline \multirow{2}{*}{ GIVEN/ NEW } & given & new \\
\cline { 2 - 3 } & $==$ & Beatrice Langosco \\
\hline \multirow{2}{*}{ EDITING } & start & end \\
\cline { 2 - 3 } & $\langle$ LS, NO WEB $>$ & $<$ CU, WEB $>$ \\
\hline
\end{tabular}

(a)

\begin{tabular}{|c|}
\hline PRESENTATION_UNIT INF_004 \\
\hline $\begin{array}{l}\text { ACTING: A2 } \\
\text { CAMERA: <LS, }-90 \text {, RIGHT_POS, FIXED_CAMERA, NO_WEB> } \\
\text { WORDS: The first owner of the Palace was the marchioness Beatrice } \\
\text { Langosco di Stroppiana. The beautiful lady, widow of an earl, } \\
\text { was very ... intimate ... with the duke Carlo Emanuele I ... }\end{array}$ \\
\hline $\begin{array}{l}\text { ACTING: C2 } \\
\text { CAMERA: }<\text { LS, }-90 \text {, CENTRE_POS, CENTRED_CAMERA, WEB }> \\
\text { WORDS: So, she was his mistress } \ldots \text { and gave him three children ... } \\
\text { illegitimate children of course, } \ldots \text { but this was normal at the time } \\
\quad \ldots \text { in fact, in } 1583 \text {, the lady married the noble man from Brescia }\end{array}$ \\
\hline $\begin{array}{l}\text { ACTING: C4 } \\
\text { CAMERA: <LS, 0, RIGHT_POS, FIXED_CAMERA, WEB > } \\
\text { WORDS: Francesco Martinengo di Malpaga, and bore other five children, } \\
\text { and was then beloved by the later duke Emanuele Filiberto for } \\
\text { her services ... }\end{array}$ \\
\hline $\begin{array}{l}\text { ACTING: E1 } \\
\text { CAMERA: <MS, 0, CENTRE_POS, FIXED_CAMERA, WEB }> \\
\text { WORDS: For her services? (red face) ... well, it was a prize for this ... } \\
\quad \text { ehm ... love story ... or morganatic marriage ... well ... } \\
\quad \text { (Carletto trips over a web wire; then stands up again and says) }\end{array}$ \\
\hline $\begin{array}{l}\text { ACTING: F1 } \\
\text { CAMERA: <CU, 0, CENTRE_POS, FIXED_CAMERA, WEB }> \\
\text { WORDS: ... I'd like not to introduce an equivocal ... }\end{array}$ \\
\hline
\end{tabular}

(b)

Figure 3. (a) Annotation metadata for the unit in (b). (b) A textual Presentation Unit (English translation from the original Italian).

ioral rules described above into a flexible script, supported by the corresponding classification of the units according to the communicative functions they achieve.

\subsection{The challenge of mobility}

Generally speaking, the literature on interactive digital storytelling provides several examples of how story coherence can be structured along a contextual feature (here, 
location), ranging from audience response in Terminal Time (where applauses orient the narration toward the ideological bias expresses by the applauses (Mateas et al. 2000)) and dramatic qualities in Façade (where a measure of dramatic intensity drives the story generation (Mateas and Stern 2005)) to emotional qualities in FearNot! (where the narration aims at the elicitation of affective states (Aylett et al. 2007)). Here, the mobility of the users challenges the fluency of storytelling, setting the need for solutions that provide:

- location-adaptive selection of the narrated facts, so that the storytelling superimposes to the visitor's physical presence in the current location;

- story synchronization with the visitor's progression through different locations, to form an overall consistent narration.

In "Carletto the spider", given the relevance of the informative goals, we decided to base the story coherence on the knowledge structures underlying the artistic and historical information to be conveyed, giving rise to ontology-based storytelling. In recent years, the use of ontologies has become widespread in new media, because the annotation of media assets with ontologies (vs. traditional approaches based on relational databases) supports the access and reuse to media repositories (Arndt et al. 2007) and improves the entire workflow of media production (Hardman et al. 2008). In cultural heritage, for example, the knowledge about art works contained in ontologies has been exploited by Aroyo et al. (2007) to generate usertailored museum visits. In particular, practical applications often rely on "light ontologies", i.e., simple taxonomies of object types that encode general-to-specific relations among concepts in a limited domain. In cultural heritage, an example of a light ontology is given by the Iconclass classification, a hierarchical description of iconographical subjects of artworks. ${ }^{1}$

In the case of "Carletto", the two main semantic dimensions along which the narrated fact can be classified are the topological and the historical ones (see Figure 4). These two dimensions account for, respectively, the requirement of the locationadaptiveness, and the requirement of story synchronization with the visitor's path. The topological dimension is inspired by the guidance role: this aspect leads to the annotation of the units, according to the topological ontology, which organizes the knowledge about the structure of the location: palace, rooms, walls and ceilings of each room, objects contained in a room (e.g., the unit in Figure 3 is about the whole palace, Palazzo Chiablese). In this ontology, concepts are mainly related by mereological (part of) relations, such as, e.g., building, rooms and room walls. The use of topological ontology to select the narrated facts guarantees that the requirement of location-adaptive of storytelling is accounted for.

The historical dimension concerns the role of gossipy narrator, and the annotation refers to a historical ontology, which contains the historical facts (and anecdotes) and characters related to the location (e.g., the unit in Figure 3 mentions two major characters, Beatrice Langosco and Carlo Emanuele I). This ontology includes two main branches, describing respectively the historical figures who lived in the palace and those who worked in it (further subdivided into painters, architects and craftsmen). The figure shows some fragments of the historical, object and topological ontologies; as it can be noticed by observing the figure, the node representing the historical character of the Duke Ferdinando di Savoia Genova (one of the owners of the Palace, instance of the class "Savoy family members") is connected to some instances of the object ontology by a relation of the type "subject_of". In fact, two of the busts contained, respectively, in the apartments (Reception room) and in

\footnotetext{
${ }^{1}$ http://www.iconclass.org/
} 


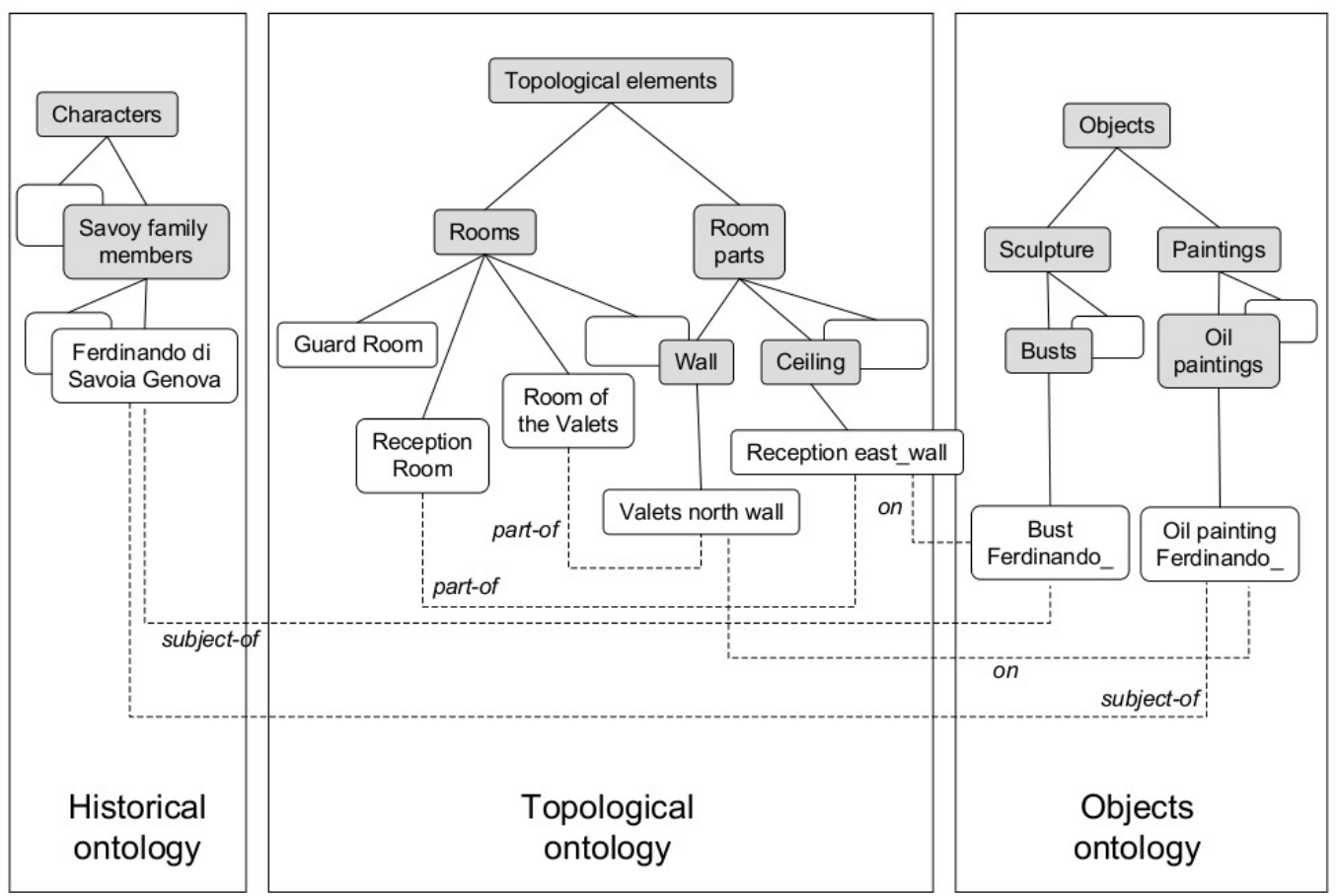

Figure 4. A fragment of the domain ontology concerning Palazzo Chiablese, including portions of three ontologies (historical, topological and object ontologies). Grey boxes represent classes, white boxes represent instances. Subclass and instance relations are represented by solid lines, non-taxonomic relations are represented by dashed lines.

the entrance hall of the Palace, represent the character of the Duke Ferdinando. The Duke Ferdinando is also depicted in an oil painting contained in the Room of the Valets.

By interleaving the use of these two ontologies in the selection of the informative units (units that convey information, achieving the informative function in the interaction script), the inner conflict of the character is exposed: the narration follows the topological units, but after a certain time in the same location has elapsed, the system switches to the historical ontology, so that the gossipy personality, reporting anecdotes and facts about individual characters, tend to emerge. The author also differentiated linguistically the topological and the historical units, written respectively to express the point of view of a professional guide vs. a passionate resident. Three other taxonomies, objects, chronology, and historical characters, respectively, are employed by the system to smooth the transitions between units by maximizing the similarity with adjacent units.

The narration is mainly structured along the topological dimension. Information units are selected by the system to form a coherent narration by taking into account the visitor's current location and the path she/he has followed in the historical site. For example, as anticipated before, if the visitor remains in the same room for a certain time, this is interpreted as an interest of the visitor towards that specific room, so the virtual character switches from the role of a professional guide to the role of a 'resident'; this is reflected by his personal involvement in the history of the location. So, the storytelling is not only aware of the location, but it also proceeds and evolves in a synchronized way with the advancement of the visit. In short, Carletto's storytelling is generated according to the following strategy:

(1) If the visitor has moved to a new room, the system sets the current ontology to the topological one and sets the focus to the current room. In this way, a generic informative unit about the room is selected.

(2) On the contrary, if the visitor remains in the same room (entered at some previous selection cycle), the system either starts or continues the description of the contents 
of the room, following the order by which items are positioned along the four walls of the room and the ceiling.

(3) Then, Carletto switches to the historical ontology, by selecting units that maximize the annotation matching, i.e. the units that include a reference to the historical ontology but still concerns the current item on the topological ontology. After the ontology switch, the system checks whether there is any non-delivered information left to say about the current room part; otherwise it moves the focus to the next room part.

Mobility also requires the development of a linguistic feature. Linear storytelling proceeds in a fixed order, so entities are introduced at some point and referred to later on. With mobility, the occasions for employing a unit also depends on the current position of the visitor and on her/his previous locations, so the exact presentation order of the units cannot be predicted in advance. So, each presentation unit is further tagged according to a given/new distinction of the discourse referents mentioned therein. A referent introduced by the unit as it was the first time in the presentation is marked "new" ("The first owner of the Palace was Beatrice Langosco di Stroppiana"); a referent assumed as already introduced in another, previously delivered unit is marked "given" ("Lady Beatrice was involved in a few love affairs"). The application maintains a history of the referents introduced for communicating a greater naturalness to the users.

A final remark about mobility concerns the orientation of visitor in the apartments, especially in relation to the detection of physical items mentioned in the narration. The didactic solution to this problem could be the distribution of tags for all the relevant objects (as it happens for museums with audio guides. However, this solution was prevented by both the dramatic requirements of "suspension of disbelief" posed the storytelling approach (that tags would have blurred) and the practical ban posed by the cultural institution that superintends the historical site, which allowed for the positioning of only a few signs (with Carletto's image), reporting the name of the rooms, and nothing else. Luckily, the evaluation results show that almost the totality of visitors were able to orient themselves and to find the items (without any explicit indications, neither on the mobile device screen, nor on site, apart from Carletto's descriptions). So, we concluded that the performed narration was very successful in keeping the attention of the audience on the content delivered, establishing a strong relationship between the virtual and the physical world.

\subsection{The challenge of technological issues}

The final issue concerns the infrastructure and device technology. In Carletto, we faced three main requirements related with the technological issues:

- the wireless infrastructure technology, which must be accommodated within the augment reality scenario of the application;

- the features of mobile device pose restrictions on the modality of delivery of the contents to the visitor;

- the restriction posed by the site curators have to be accounted for in the design of the technological infrastructure.

As for the wireless infrastructure, the problem was to devise a suitable metaphor to realize the augmented reality without generating a cognitive overload for visitors, so we resorted to the metaphor of the webcam, described in the Section 3.1. Then, in order to keep the interaction simple and keep the interface free from a multitude of commands, the assumption of a strong guidance at the interactional level, rooted in the metaphor of the guided visit, turned out to be functional to the goal of keeping the user interface simple. 
The localization of the visitor was limited to the room level (so, object proximity was not taken into account) and was based on a method that measures the signal strength of pre-installed 802.11 Wireless Access Points (Haeberlen et al. 2004), an approach suitable to locate devices in macro-areas of indoor locations.

To prevent problems in locating the visitor, it was decided that the interface would display a feedback of the location detected by the application and provide strategies for guiding the visitors even in periods where the signal was absent (see the location in Figure 2). Storytelling revealed itself a suitable scenario for this sort of strategies, thanks to the character's personal capacities of entertainment, with tales related to his own private life when the communication was lost and location could not be detected. In the latter cases, in fact, Carletto respectively talked about himself or about the location in general, or invited the user (through the directive function) to move slightly to regain the lost connection (in terms of the metaphor of the webcam, to regain visibility for Carletto). The robustness of the wireless infrastructure is also relevant for the overall success of the application. The evaluation showed that the visitors who experienced frequent localization problems (due to device failures of the wifi network service) were consequently less satisfied with the visit experience.

Another relevant issue consists of the constraints posed by the use of a certain type of mobile device, PDA in our case, on the modality of presentation. In particular, with the audiovisual modality supported by a PDA, visual continuity is required through the adjacent units selected on-the-fly during the interaction with the user. As a solution, visual features of the audiovisual clips that realize the logical units of the presentation were annotated, so that editing rules could be applied when selecting the most appropriate continuation. Editing features were employed to edit the narration units, possibly interposing an audiovisual segment (called a transition Unit), with the aim of obtaining visual fluency (see complete description by Biral et al. (2003)). The editing rules were inspired by the style of continuity editing, "a dominant editing style throughout western film history", used to "ensure narrative continuity" by means of a smooth flow from shot to shot in order to convey the illusion of spatial and temporal continuity (Bordwell and Thompson, Reisz 2006, 1968).

The client-server system architecture was implemented on hardware available on the consumer market and mostly on open-source software. The client, written in Java, ran on the PDA ASUS A636 (PocketPC series). Also the server was implemented in Java, while the database system that hosts the units is MySQL. The video player was based on a Flash player. The overall bitrate of a video (PDA screen resolution), including sound, was about $400 \mathrm{Kbit} / \mathrm{sec}$, enough to accommodate the 20 people that could be inside the apartments at the same time.

The last requirement about the technology infrastructure concern the compliance with the site and the restrictions posed by the curators and site managers. In order to implement the continuous communication between the character and the visitor, mobile storytelling must find the most adequate technology: mobile technology, multimedia installations in the key areas of the site, etc. The chosen devices can be specially-designed or off-the-shelf devices. In the case of "Carletto", off-theshelf mobile devices were chosen and location awareness was obtained by using a wireless network. The main reason for this choice was the impossibility of setting installations (apart from a few removable signs to label the rooms) in the location, due to the temporary nature of the application and the fact that the location was normally closed to the public. So, we resorted to standard, commonly available PDAs and relied on the pre-existent wireless network lo localize the position of the PDAs. 


\section{Discussion}

In this section, we address the major issues about mobile-based storytelling, as they emerge in Section 2, with the goal of recapitulating the lesson learned from "Carletto the spider" and generalize it to the design of similar applications. In particular, we focus on the following issues:

- the orthogonal axes of character and plot, respectively: how they can be accounted for in practical mobile applications;

- the location-awareness: how it can be successfully managed in storytelling;

- the distinction between template-based and emergent storytelling: how they affect the production and runtime behavior of the system;

- the paradigm of virtual agents: how they can be integrated in storytelling without disrupting the story tenets.

Concerning the character/plot distinction, the evaluation confirmed the design assumption that the construction of socially-aware, believable character provides a framework that accommodates the requirements posed by mobile-based storytelling. In "Carletto the spider", storytelling is embedded in an interaction script that encodes the social aspects of the "guided visit" metaphor according to a carefully crafted strategy of behavior. Following the film scripting traditions (McKee 1997), the plot (i.e., the script driving the character's behavior) was designed according to the prescription that conflicts make the story advance. The intrapersonal conflict of Carletto as a guide and a resident is responsible for switching among different topics and attitudes during the narration. Inter-personal conflicts introduce opponents, thus making the audience empathic with the hero according to the process described by Campbell (1949). For example, Carletto complains about the cleaners who chase him and remove his webs, and this allows for an invitation to the visitor to change the room.

The effectiveness of the effort put in the construction of the character is witnessed by a number of findings. Carletto was perceived as a funny character, sometimes annoying, but lovely, and above all a friendly and unconformist guide, and were inclined to follow its advices. Some visitors were even completely directed by Carletto, waiting for its advices about what to see and where to go. The mostly associated personalities were the "talking cricket" (from Collodi's "Pinocchio"), the "travel mate", and only at the third place the "guide", so confirming that the presence of storytelling, though subordinate to visit guidance is well perceived by the audience. The "suspension of disbelief" was confirmed by the ethnographic observations: sometimes, elder visitors tried to speak to Carletto, directly addressing him with spontaneous comments; some children thought the Carletto was really hidden somewhere in the ceilings.

Concerning the location-awareness in storytelling, the design assumption that structuring the story advancement along the topological dimension - according to a general to particular progression - has proven successful. In the quantitative analysis of the evaluation data, we found that a general good experience of the visit was related with a satisfying fruition of the location-based focusing strategy. The ontology-based navigation of topics (that addresses more specific topics when the visitor remains in some location for some time) is a storytelling format that works well in the visit to historical sites, modulating the communicated knowledge according to the interests of the visitors, implicitly expressed by their paths in the location. According to the classification of pervasive storytelling proposed by Gentes and Jutant (forth), the use of the historical ontology as the main drive for storytelling qualifies the generated narration as "mimetic" storytelling, i.e., a 
narration style that does not change the user's perception of the site, typical of museum guides. However, the resort to the historical and anectodal dimension for building the character of Carletto, with his fictional conflicts and the evocation of non-existent characters, make it slightly shift towards the "uncanny" type of storytelling.

The validity of this strategy is also confirmed by the visitors' ability to orient themselves and to find the items while they experienced the augmented reality of Carletto. So, we concluded that the performed narration was very successful in keeping the attention of the audience on the content delivered, establishing a strong relationship between the virtual and the physical world. Also, the idea of subordinating storytelling to visit guidance was relevant to the goal of maintaining the relationship between the physical and the virtual world; giving more relevance to storytelling would drag visitors completely on the virtual side, losing contact with the physical site.

Concerning the distinction between template-based and emergent approaches in storytelling, "Carletto the spider" belongs to the first type. In fact, it builds on the assumption that a sufficiently flexible script can account for the mobile and interactive issues faced by the application, while enforcing a strong authorial control. The flexibility of the script is limited to the social situations encompassed by the interaction design, thus providing a general template that is filled, runtime, by contextually appropriate units. A major drawback of this approach is the burden posed on the production of the units by the need to annotate them with the relevant information for the runtime selection.

The possibility of mapping the annotation developed for Carletto onto general models, however, proves the possibility of generalizing this development methodology to similar location-based, interactive storytelling applications. In the specific field of metadata for mobile applications, in particular, two approaches are relevant for generalizing the lesson learned about annotation (Wither et al. (2009), Tryfona and Pfoser (2005)). Wither et al. (2009) propose a taxonomy of annotation types for outdoor augmented reality, that can be adapted to our application. The annotation of the topic of the units in Carletto (Fig. 3)) can be classified as belonging to the direct annotation type, where direct annotations are defined as the information that directly concerns the content of the objects in the physical location. In Carletto, these objects consist of rooms and the items they contain. Then, given the classification of the dimensions of Wither et al. (2009), what they describe as the semantic dimension is suitable to describe the content of the topic annotations, since they are based on ontologies (the topological and the historical ontology, that allow the system to adapt to the location of the visitor by organizing the topics into a consistent narration). The framework by Tryfona and Pfoser (2005) proposes a tripartite model for describing the ontological status of the location-based data. This model encompasses domain data, content data and application data. According to this model, the ontologies on which Carletto relies on incorporate both domain data about the location (the topological ontology) and content data about the the non-locative properties of the historical site (the historical and object ontology).

The lesson learned in such a case is the imperative need of a strong cooperation between the author and the software engineers. The subordination of storytelling to visit guidance and the effectiveness of the focusing strategy to drive storytelling require an adequate tagging of the units and a capacity to figure out all the sequences in which that unit will be employed. Very effective is the software strategy of stepwise refinement through prototypes that the author can use from the beginning of the system implementation. In the case of "Carletto the spider", we found very useful to implement an interface through which the author could work 
autonomously by inserting and tagging new units within the system, and testing their effectiveness within storytelling.

Concerning the use of virtual agents in storytelling applications, the evaluation revealed that the reactivity of the character - a major trait of the paradigm of virtual agents - is appreciated by the users. The request for a more active interaction (at various levels), with the possibility of asking questions to Carletto, emerged for the questionnaires. However, given the general good acceptance of the application, we argue that interactivity should be graded on demand and continuously traded-off with the guidance of the interaction. A high level of interactivity, in fact, may negatively affect the construction of the character, thus disrupting the main design assumption incorporated in the application, i.e., that a well recognizable character, cast into a socially believable interaction, can successfully embed storytelling in a mobile application. Notwithstanding this caveat, forms of active input can be seamlessly integrated into the interaction strategy by using the ontological knowledge to recommend related contents and to support semantic search, without disrupting the storytelling approach (an example of system redesign to implement a character-based search interface is described by Borini et al. (2009)). The request for personalized interaction, on the contrary, requires the construction of a user model to differentiate the interaction style and the presentation level for individual users.

Finally, a shortcoming of our approach is that it tends to isolate visitors. In our case, at the beginning, visitors tend to be lonelier, isolated, and with limitations to their ability to listen and to speak with others; after a while, some of them regain the group, and exchange information and comments about the presentation (that usually does not occur in the same sequence), looking at each other's devices. This is in line with the typical behavior of heritage site visitors, as described by Aoki et al. (2002), who often go in groups. Aoki et al. propose a strategy to cope with behavior in museum settings. A different approach to leverage the visit experience by exploiting the social aspect of groups is proposed in this issue by Callaway et al. (forth), who induce a well calibrated mismatch among the individual experiences as a way to induce group conversation. However, for the sake of completeness, the observations also demonstrate that there are visitors who prefer more individual experiences (even if they get to the site in groups). Again, the lesson learned is to prefer a flexible strategy in allowing the share of experience among visitors and be ready for providing privacy when requested (such as a command of hook-on/get-away-from a group). Since a few years have passed since the installation was designed, the application could be redesigned to include social elements, thanks to the current diffusion of the paradigm of social networks and the improved connectivity among mobile devices.

\section{Conclusion}

This paper illustrates a storytelling-based application, with an anthropomorphic spider character, playing the role of a guide to a historical site, in a dramatic performance staged on the screen of a mobile device. The application mixes a flexible presentational strategy, modeled upon the guided visit protocol, and the predefined units that are to be edited during the presentation. The on-line, adaptive editing of the presentation accounts for the path followed by the visitor in the historical site. Since the units were written according to the paradigm of storytelling, the resulting presentation takes the form of a dramatized story narration, with the character of Carletto threading anecdotes while he follows the visitor in the exploration of 
the location. This methodology supported different platforms for delivery (PDA and WWW), always keeping the same features of location-based character-enacted storytelling.

The paper focused on the challenges posed to the storytelling paradigm by the contextual constraints of a physical site and of a specific application, with the issues of interactivity, mobility and device technology. The lesson learned from this experience confirms the importance of the storytelling-based approach in the emotional engagement of the audience, but at the cost of keeping storytelling subordinate to other metaphors (in our case, visit guidance). On the other hand, guidance is also a reason of the success of the initiative, given the expectations of the audience for a more informative than a highly entertaining application. We believe that applications such as "Carletto the spider" can improve the communication strategy of a cultural heritage site in two main ways: by conveying more information to the visitors, and, thanks to the possibility of delivering the application on the web, by continuing to support the knowledge of the historical site also after the physical visit; by emotionally engaging the audience, leaving a persistent memory of the site through the character's personality, who acts as a representative of the site identity.

\section{Acknowledgements}

We thank Cristina Gena, Fabrizio Nunnari, and Antonio Pizzo for their contribution to the theoretical study and the application "Carletto the spider".

\section{References}

Aoki, P.M., Grinter, R.E., Hurst, A., Szymanski, M.H., Thornton, J.D. and Woodruff, A., 2002. Sotto Voce:Exploring the Interplay of Conversation and Mobile Audio Spaces. Minneapolis, Minnesota, USA.

Arndt, R., Troncy, R., Staab, S., Hardman, L. and Vacura, M., 2007. COMM: designing a well-founded multimedia ontology for the web. The Semantic Web, $30-43$.

Aroyo, L., Brussee, R., Gorgels, P., Rutledge, L., Stash, N. and Wang, Y., 2007. Personalized Museum Experience: The Rijksmuseum Use Case. 11-14 April., San Francisco, CA.

Ashley, S., 2007. The Changing Face of Heritage at Canada's National Historic Sites. International Journal of Heritage Studies, 13 (6), 478-488.

Aylett, R., Vala, M., Sequeira, P. and Paiva, A., 2007. FearNot!-An Emergent Narrative Approach to Virtual Dramas for Anti-bullying Education. LNCS, 4871, 202.

Ballagas, R., Kuntze, A. and Walz, S., 2008. Gaming tourism: Lessons from evaluating rexplorer, a pervasive game for tourists. Pervasive Computing, 244-261.

Bernsen, N.O. and Dybkjaer, L., 2004. Domain-Oriented Conversation with H.C. Andersen. 142-153.

Bickmore, T. and Cassel, J., 2005. Social Dialogue with Embodied Conversational Agents. Advances in Natural Multimodal Dialogue Systems., Vol. 30 Springer, Netherlands, 23-54.

Biral, F., Lombardo, V., Damiano, R. and Pizzo, A., 2003. Cyrano goes to Hollywood: a drama-based metaphor for information presentation. 17-24.

Bordwell, D. and Thompson, K., 2006. Film art : an introduction. Boston: McGraw Hill. 
Borini, E., Damiano, R., Lombardo, V. and Pizzo, A., 2009. DramaSearch. Character-mediated search in Cultural Heritage. 554-561.

Bruner, J., 1991. The narrative construction of reality. Critical Inquiry, 18(1), 1-21.

Callaway, C., Stock, O. and Dekoven, E., ????. Mobile Drama in an Instrumented Museum: Inducing Group Conversation via Coordinated Narratives. Taylor \& Francis.

Campbell, J., 1949. The Hero with a Thousand Faces. Princeton: Princeton University Press.

Carroll, N., 2001. Beyond Esthetics: Philosophical Essays. New York: Cambridge: Cambridge University Press.

Clark, K., 2002. Inspired 3D Character Animation. Premier Press.

Damiano, R., Gena, C., Lombardo, V., Nunnari, F. and Pizzo, A., 2008. A stroll with Carletto. Adaptation in drama-based tours with virtual characters.. User Modeling and User-Adapted Interaction.

Damiano, R., Lombardo, V., Nunnari, F. and Pizzo, A., 2006. Dramatization meets information presentation. Riva del Garda, Italy.

Dow, S., Lee, J., Oezbek, C., MacIntyre, B., Bolter, J.D. and Gandy, M., 2005. Exploring Spatial Narratives and Mixed Reality Experiences in Oakland Cemetery. Valencia, Spain, 51-60.

Ericsson, M., 2003. Enchanting Reality-A vision of big experiences on small platforms. .

Gentes, A. and Jutant, C., ????. The Game Mechanics of Pervasive Applications: Visiting the Uncanny. Taylor \& Francis.

Gershon, N. and Page, W., 2001. What Storytelling Can Do for Information Visualization. Communications of the ACM, 44(8), 31-37.

Greimas, A., 1977. Elements of a Narrative Grammar. Diacritics, 23-40.

Grosz, B.J. and Sidner, C.L., 1986. Attention, Intentions, and the Structure of Discourse. Computational Linguistics, 12, 175-204.

Haeberlen, A., Flannery, E., Ladd, A.M., Rudys, A., Wallach, D.S. and Kavraki, L.E., 2004. Practical robust localization over large-scale 802.11 wireless networks. Philadelphia, PA, USA New York, NY, USA: ACM Press, 70-84.

Hansen, F., Kortbek, K. and Grønbæk, K., ????. Mobile Urban Drama - Interactive Storytelling in Real World Environments. Taylor \& Francis.

Hardman, L., Obrenović, Ž., Nack, F., Kerhervé, B. and Piersol, K., 2008. Canonical processes of semantically annotated media production. Multimedia Systems, 14 (6), 327-340.

Kopp, S., Gesellensetter, L., Kraemer, N. and Wachsmuth, I., 2005. A Conversational Agent as Museum Guide - Design and Evaluation of a Real-World Application. .

Laurel, B., 1993. Computer as Theater. Reading, MA: Addison Wesley Longman.

Leon, J. and Fisher, M., 2006. The Use of Virtual Characters to Generate Teachable Moments. In: J. Trant and D. Bearman, eds. Museums and the Web 2006: Proceedings, http://www.archimuse.com/mw2006/papers/leon/leon.html, Toronto.

Lombardo, V., Nunnari, F., Damiano, R., Pizzo, A. and Gena, C., 2008. The canonical processes of a dramatized approach to information presentation. Multimedia Systems Journal. Special Issue on the Canonical Processes of Multimedia Production. Springer, 14 (6), 385-393.

Maestri, G., 1996. Digital Character Animation. New Riders.

Magelssen, S., 2006. "This Is a Drama. You Are Characters": The Tourist as Fugitive Slave in Conner Prairie's "Follow the North Star". Theatre Topics. The Johns Hopkins University Press., 16 (1), 19-34.

Malcolm-Davies, J., 2004. Borrowed robes: The educational value of costumed in- 
terpretation at historic sites. International Journal of Heritage Studies, 10 (3), $277-293$.

Mateas, M. and Stern, A., 2005. Structuring Content in the Faade Interactive Drama Architecture. .

Mateas, M., Vanouse, P. and Domike, S., 2000. Generation of Ideologically-Biased Historical Documentaries. August., 36-42.

McKee, R., 1997. Story. New York: Harper Collins.

Montola, M., Stenros, J. and Waern, A., 2009. Pervasive games: Theory and design. Morgan Kaufmann.

Nelson, M., Mateas, M., Roberts, D. and Isbell, C., 2006. Declarative optimizationbased drama management in interactive fiction. IEEE Computer Graphics and Applications, 26 (3), 32-41.

Pletinckx, D., Silberman, N. and Callebaut, D., 2003. Heritage presentation through interactive storytelling: a newmultimedia database approach. Journal of Visualization and Computer Animation, 14, 225-231.

Prince, G., 2003. A Dictionary of Narratology. University of Nebraska Press.

Propp, V., 1968. Morphology of the Folktale. University of Texas Press.

Reid, J., Clayton, B., Melamed, T., Hull, R., Stenton, P., Peirce, A., Gidlow, C. and Holmes, S., 2008. The design of Prisoner Escape from the Tower: an interactive location aware historical game.. .

Reisz, K., 1968. The technique of film editing. London: Focal Press.

Si, M., Marsella, S. and Pynadath, D., 2005. Thespian: Using multi-agent fitting to craft interactive drama. 21-28.

Spierling, U., 2005. Interactive digital storytelling: towards a hybrid conceptual approach. .

Stenton, S., Hull, R., Goddi, P., Reid, J., Clayton, B., Melamed, T. and Wee, S., 2007. Mediascapes: Context-aware multimedia experiences. IEEE MULTIMEDIA, 98-105.

Swartout, W., Traum, D., Artstein, R., Noren, D., Debevec, P., Bronnenkant, K., Williams, J., Leuski, A., Narayanan, S., Piepol, D. et al., 2010. Ada and grace: toward realistic and engaging virtual museum guides. 286-300.

Thomas, J. and Young, R., 2006. Author in the loop: Using mixed-initiative planning to improve interactive narrative. .

Tryfona, N. and Pfoser, D., 2005. Data semantics in location-based services. Journal on Data Semantics III, 168-195.

Wither, J., DiVerdi, S. and Hoellerer, T., 2009. Annotation in outdoor augmented reality. Computers \& Graphics, 33 (6), 679-689. 